\title{
Investigation of seasonal low temperature effects on dynamic behavior of prototype reinforced concrete minaret by using experimental and numerical studies
}

\author{
K. Hacıefendioğlu*1 ${ }^{*}$ F. Birinci ${ }^{2}$ \\ ${ }^{1}$ Karadeniz Technical University, Department of Civil Engineering, Trabzon, Turkey \\ ${ }^{2}$ Ondokuz Mayls University, Department of Civil Engineering, Samsun, Turkey
}

\begin{abstract}
In this study, an experimental and numerical study is carried out to estimate the dynamic behavior of reinforced concrete minaret subjected to low temperatures during earthquakes. For this purpose, 1:20 reduced scale model of an actual reinforced concrete minaret was built in the laboratory. In order to estimate the effects of the seasonal low temperatures on the minaret, the model was placed into a large volume freezer and then were exposed to low temperatures of $-50 \mathrm{C},-100 \mathrm{C},-200 \mathrm{C}$ and $-300 \mathrm{C}$, respectively. For each temperature, the model was taken outside the freezer and by using the shaking table, the maximum acceleration values at the top and middle region of the minaret were obtained with accelerometers mounted on the minaret. The maximum acceleration values illustrated that seasonal low temperatures affect seismic behavior of the prototype reinforced concrete minaret model.
\end{abstract}

\section{Keywords}

Seasonal low temperature; Seismic behavior; Shaking table; Seasonal cold region; Reinforced concrete minaret.

Received: 25 June 2019; Accepted: 27 September 2019

ISSN: 2630-5763 (online) (C 2019 Golden Light Publishing® All rights reserved.

\section{Introduction}

As many cold regions of the world, some cold regions of our country are also located on active seismic zone. As well-known from the scientific studies, seasonal freezing importantly affects the structures located in the cold regions. The identification of the resistance and lives of structures in the Eastern Anatolia and Southeast Anatolia regions, on the earthquake zone, of Turkey is an important issue to be examined.

The international studies show that the crystal of materials changes due to the seasonal low temperature. Accordingly, the modulus of elasticity, Poisson's ratio and unit weight of the materials show significant changes [1-3] Sound waves caused by the oscillation or vibration of the particles within the materials, in terms of knowledge of basic and physical properties of the materials are very important [4].

The non-destructive ultrasonic method for determining the material properties can be used in many applications, such as the medical and biological applications, underwater measurements of ultrasonic flaw detection etc. Nowadays, this method finds a wide application area for the minerals, sands, rocks and unfrozen soils [4-7]. In

* Corresponding author

E-mail: kemalhaciefendioglu@ktu.edu.tr 
recent years, this method is additionally used to determine the mechanical properties of frozen soil media.

Considering the factors mentioned above depending on the material properties, the effects of seasonally cold are very important for estimating the seismic behavior of structures built in cold regions, subjected to earthquake ground motion [813]. In earthquake regions of our country under the influence of extreme cold, seasonal, or are frequently built of the reinforced concrete minarets have been or are frequently built. The destruction of the minarets located in active earthquake zone in Turkey causes many life and property losses from a possible earthquake.

For this purpose, a reduced scale model was prepared to predict the seismic behavior of a real reinforced minaret. The dynamic behavior of this model exposed to low temperatures was determined by an earthquake shake table by means of accelerometers. For the effects of freezing and icing during earthquake, prototype model (1:20 reduced scale model) of a reinforced concrete minaret was placed in the large volume freezer and kept at low temperatures and the structural behavior of the model was investigated.

\section{Shaking table mechanism}

In terms of knowledge of the behavior of structures during earthquakes, the importance of Earthquake Engineering Simulator tables (shake table) is rapidly increasing. In this study, in order to determine the seismic behavior of a reduced-scale reinforced concrete minaret model under the influence of different low temperatures, the singleaxis vibration table moving horizontally, which has dimensions of $45.72 \times 45.72 \mathrm{~cm} 2$ has been used. The shaking table has a capacity of $15 \mathrm{~kg}$. To be able to carry over $15 \mathrm{~kg}$, the wheel carrier system connected to shaking table has been developed. In this way, the seismic behavior of the models up to $50 \mathrm{~kg}$ can be conducted. Shaking table with a weight of $27.22 \mathrm{~kg}$, the measurements in the frequency range of $0-20 \mathrm{~Hz}$ can be performed with $2.5 \mathrm{~g}$ maximum acceleration and $83.83 \mathrm{~cm} / \mathrm{s}$ maximum speed capability. The acceleration records of actual earthquakes are scaled depending on the movement capability of the shaking table. The investigations on the reinforced concrete minaret model are carried out by using the three accelerometers. These accelerometers located on the different regions of the minaret model transfer to computer the acceleration values depending on the time. So that, the seismic behavior of the reduced-scale reinforced concrete minaret can be estimated. Fig. 1 shows the shaking table named as Shake Table II.

\section{Earthquake record}

In this study, $1940 \mathrm{El}$ Centro earthquake is used to determine the seismic behavior of the reinforced concrete minaret subjected to low temperature. The earthquake acceleration records have been reduced with a certain amount in order to stay within the table limits. In this case, the actual earthquake lasted 53.75 seconds, provided that the changeover of acceleration amplitudes has become 31-second recording (Fig. 2). This acceleration record was applied to the shaking table and the acceleration values were obtained from accelerometers placed to the top and second cheers of the minaret.

\section{Experimental application}

In this study, 1:20 reduced scale model of an actual reinforced concrete minaret was used. The quality of concrete used in this model has been found to be $\mathrm{C} 30$ by using the ultrasonic testing method. The minaret model has been strengthened by reinforced which consist of the fine iron wires.

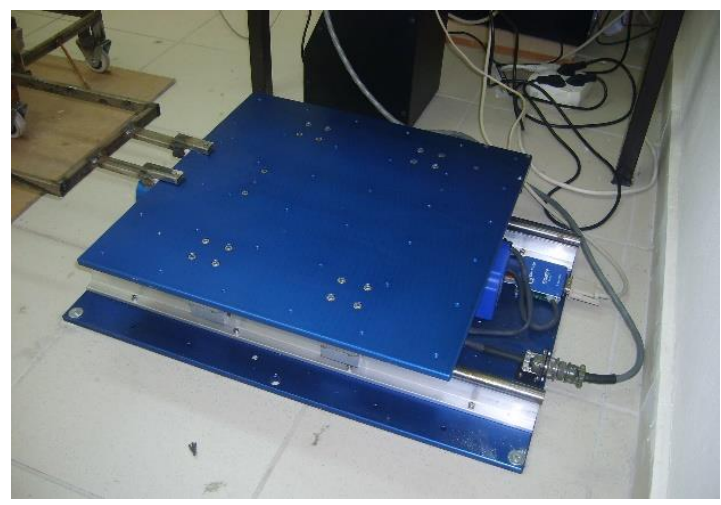

Fig. 1. Shaking table 


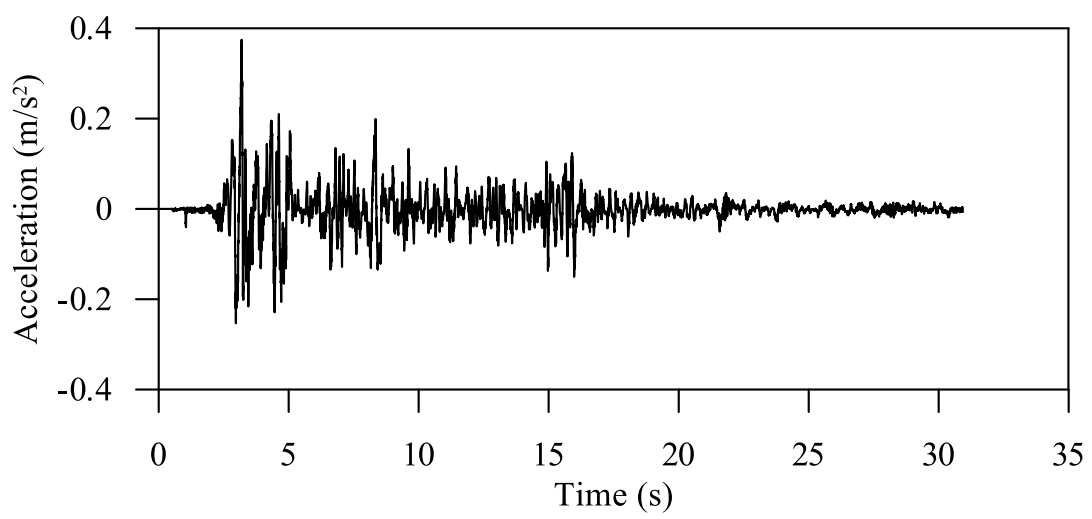

Fig. 2. 1940 El-Centro Earthquake record

The reduced minaret model was fixed to the previously mentioned wheel carrier system and the three accelerometers, respectively, were placed to the top (2nd floor) and middle body region (1st floor) of the minaret and the shaking table. Then, the maximum acceleration values are obtained. Fig. 3 and Fig. 4 shows the reduced scale model and dimensions of the minaret, respectively.

\subsection{Accelerations}

In this study, 1940 El-Centro earthquake reduced in accordance with the shaking table was used. In order to examine the effects of the seasonally cold on the minaret, the model was placed into a large volume freezer and then were exposed to low temperatures of $-50 \mathrm{C},-100 \mathrm{C},-200 \mathrm{C}$ and $-300 \mathrm{C}$, respectively. For each temperature, the model was taken outside the freezer and by using the shaking table, the maximum acceleration values at the top and middle region of the minaret were obtained with accelerometers mounted on the minaret. The acceleration values depending on time derived from the accelerometers placed on the first and second floor were shown in Fig. 5 (a-d) and the maximum acceleration values of the first and the second floor were also illustrated in Fig. 6 (a-b), respectively. As it can be seen in the figures, decreasing in temperature (negative direction) causes decreasing the maximum acceleration values obtained from the 1st and 2nd floors. Analysis results show that the low temperature is effective on the concrete material properties. Because the seasonal cold increases the rigidity of the material thus the system, the decreasing in temperature leads to decreasing the acceleration values.

\section{Numerical Application}

\subsection{Mechanical properties of frozen concrete}

The ultrasonic measurement system is one of the most important methods to determine the dynamic mechanical properties of the materials. The ultrasonic sing-around method is based on the refraction of waves induced in a material and allows for measurement of dilatational and shear wave velocities using the same one system. The dynamic mechanical properties, elastic modulus, Poisson's ratio and density, may be calculated from knowledge of the dilatational and shear wave velocities propagating through the material subjected to low temperatures.

First, a sample specimen, which is the same concrete used in reinforced concrete minarets model, was prepared. The dimensions of the specimen are $15 \mathrm{~cm}$ long x $15 \mathrm{~cm}$ wide. The sample was then placed into the large volume freezer at temperatures of $-50 \mathrm{C},-100 \mathrm{C},-200 \mathrm{C}$ and $-300 \mathrm{C}$, respectively, and was frozen quickly for a sufficient period of time. Dilatational wave velocities and shear wave velocities for the temperature mentioned above were calculated. While determining the dynamic properties of the frozen concrete sample specimen for the various conditions, we take the frozen concrete specimen as an isotropic medium. 

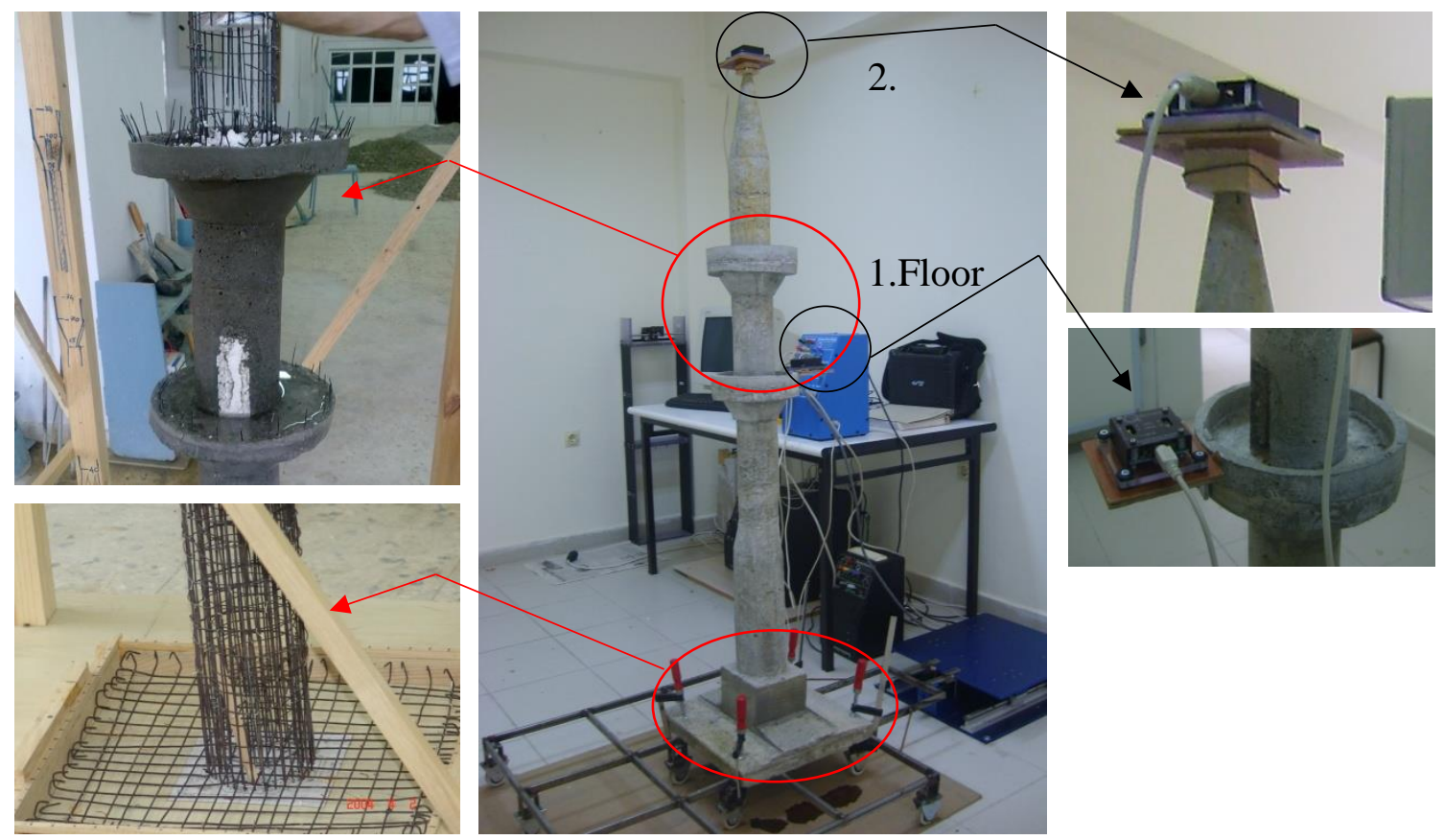

Fig. 3. 1:20 reduced scale minaret model
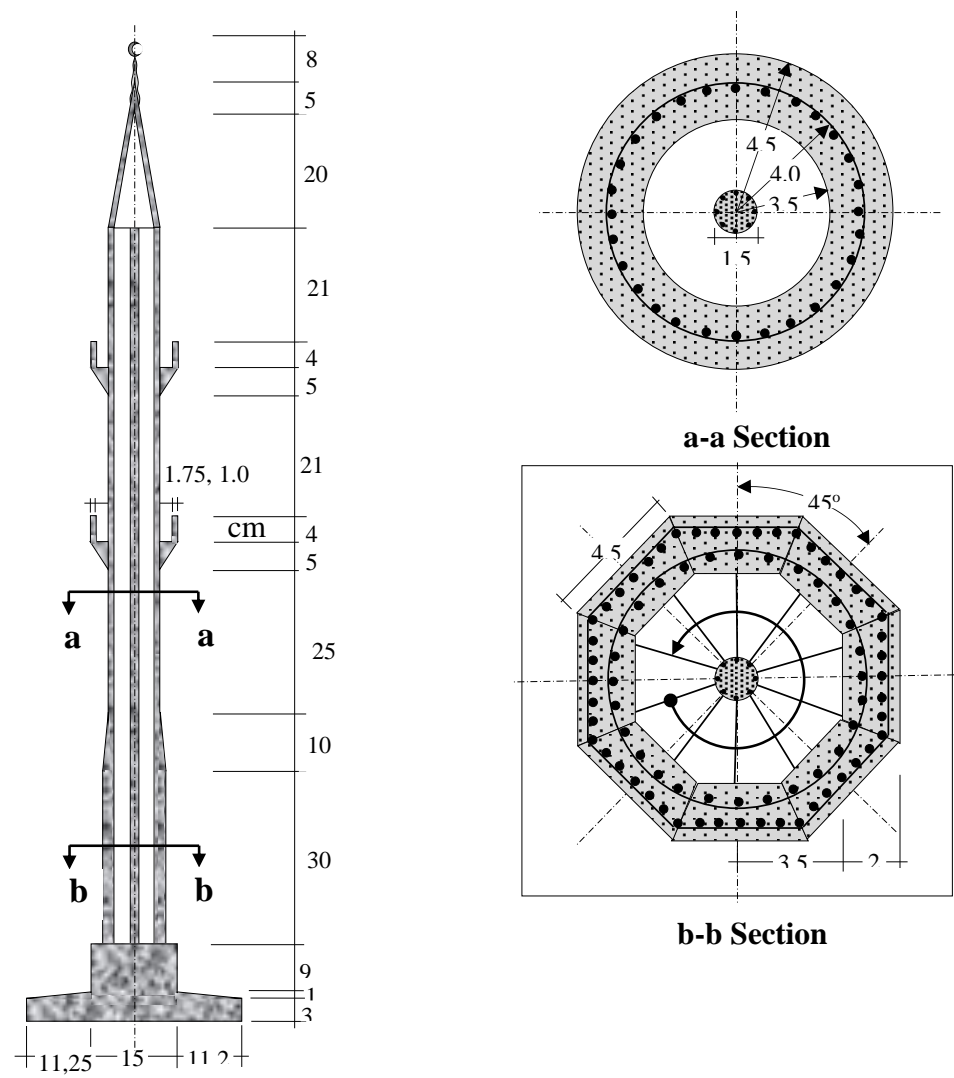

b-b Section

Fig. 4. Dimensions of 1:20 reduced scale minaret model 


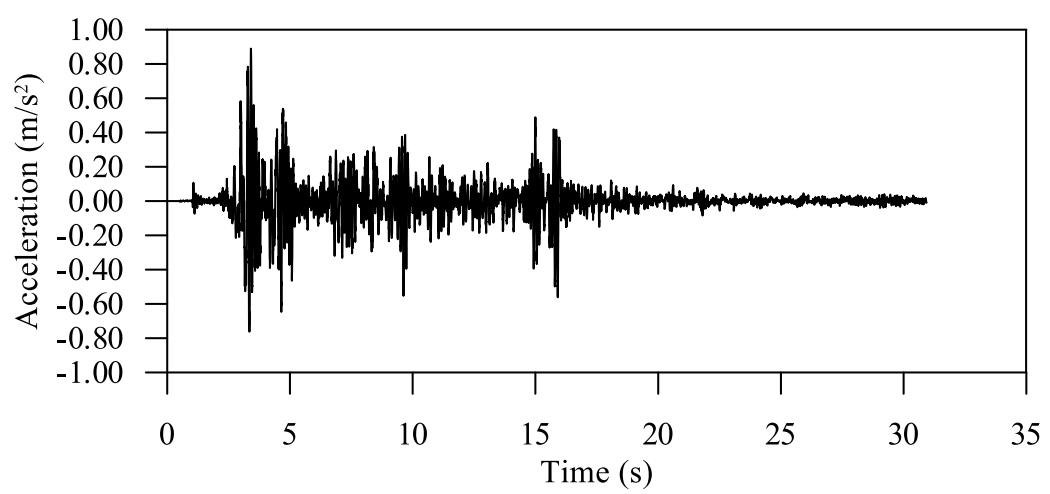

(a)

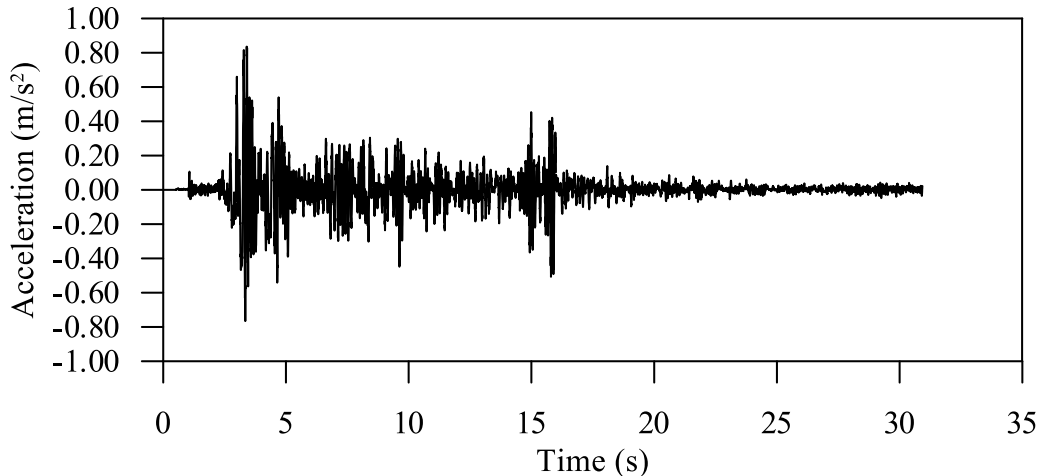

(b)

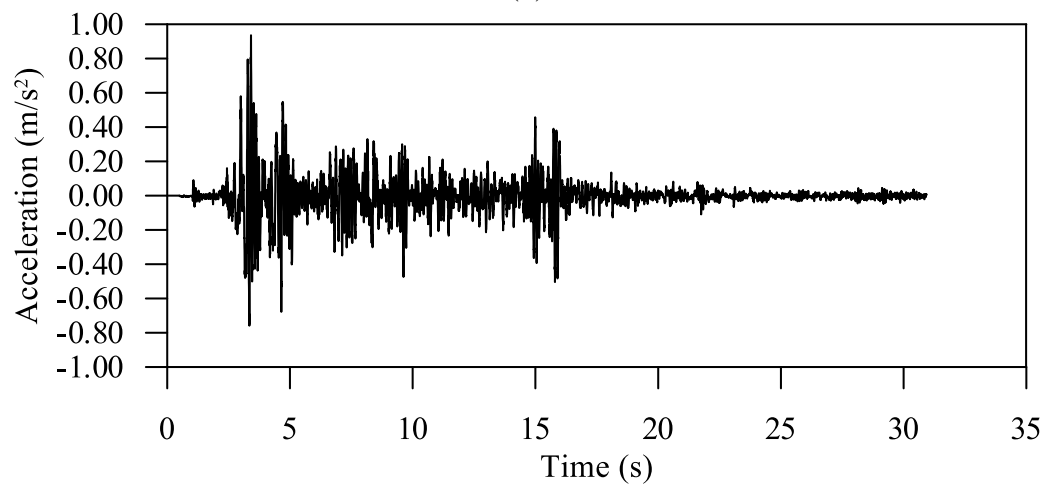

(c)

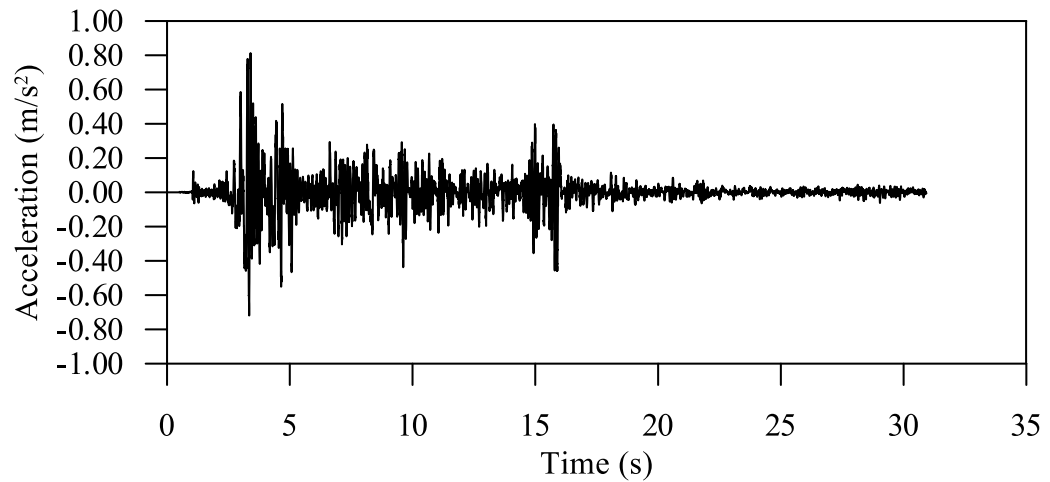

(d)

Fig. 5. Acceleration time history values at (a) $-5^{\circ} \mathrm{C}$, (b) $-10{ }^{\circ} \mathrm{C}$, (c) $-20{ }^{\circ} \mathrm{C}$ ve (d) $-30{ }^{\circ} \mathrm{C}$ temperatures for second floor 


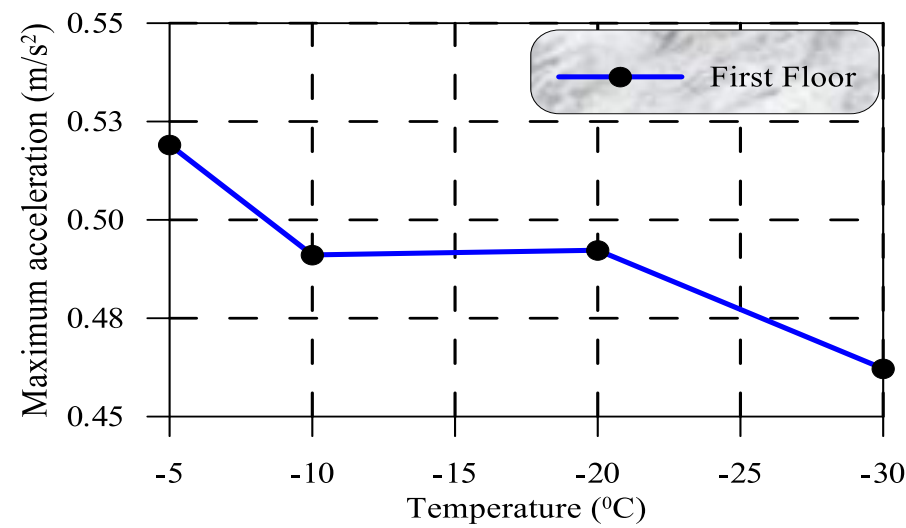

(a)

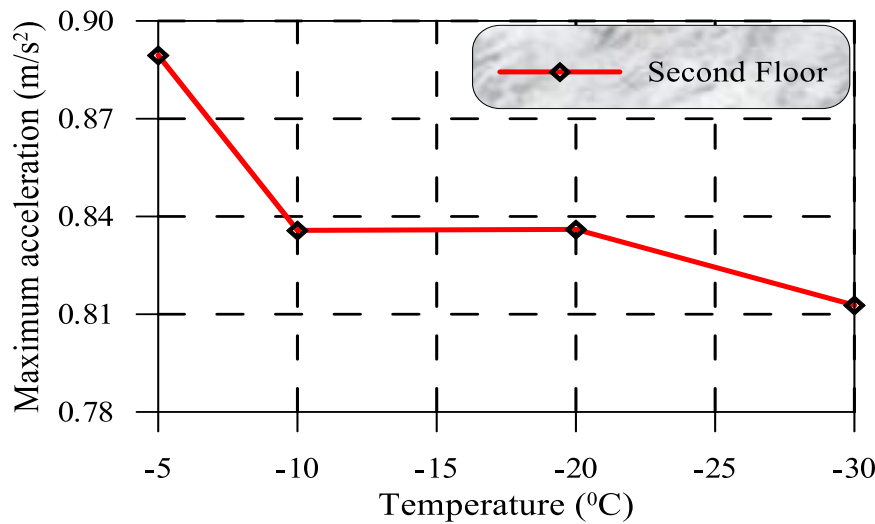

(b)

Fig. 6. Maximum accelerations depending on the low temperature for (a) first floor (b) second floor

The dynamic modulus may be calculated from knowledge of the velocities of dilatational and shear waves. So, the dynamic elastic modulus E, dynamic shear modulus G, Poisson's ratio $\square$, and density $\rho$ can be calculated as follows:

$\rho=0.2 \mathrm{~V}_{\mathrm{p}}+1.6$

$v=\frac{\left(1-2\left(\mathrm{~V}_{\mathrm{s}} / \mathrm{V}_{\mathrm{p}}\right)^{2}\right)}{\left(2-2\left(\mathrm{~V}_{\mathrm{s}} / \mathrm{V}_{\mathrm{p}}\right)^{2}\right)}$

$\mathrm{G}=\rho \mathrm{V}_{\mathrm{s}}^{2}$

$\mathrm{E}=2(1+v) \mathrm{G}$

where $\mathrm{E}(\mathrm{Mpa})$ is the dynamic elastic modulus, $\mathrm{G}$ $(\mathrm{MPa})$ is the dynamic elastic modulus, is the Poisson's ratio, Vp, Vs are the velocity of the compressional and shear wave $(\mathrm{km} / \mathrm{s})$, respectively, ( ) is the density of the specimen.
Table 1 shows the various temperature conditions of the concrete specimen tested. Dynamic elastic and shear modulus, Poisson's ratio and density are illustrated in Table 1 for a range of temperatures.

Based on the above-Table 1, the dynamic properties of frozen concrete which is $\mathrm{C} 30$ by using the ultrasonic testing method can be determined. The dynamic elastic modulus, densities and Poisson's ratios are presented in Figs. 7(a-c), where the dynamic elastic modulus, densities and Poisson's ratios is plotted as a function of temperature. As seen in the figures, the dynamic elastic modulus, densities and Poisson's ratios will increase with temperature decreasing. According to regression analysis on the test data, the relationship between the dynamic elastic modulus, densities, Poisson's ratios and temperature can be described in Figs.7 (a-c). 
Table 1. Dynamic mechanical properties of concrete specimen with respect to low temperatures

\begin{tabular}{|c|c|c|c|c|c|}
\hline Temperature $\left({ }^{0} \mathrm{C}\right)$ & $\begin{array}{c}\text { Room } \\
\text { temperature }\end{array}$ & -5 & -10 & -20 & -30 \\
\hline Poisson's Ratio & 0.27 & 0.27 & 0.26 & 0.27 & 0.30 \\
\hline Density $\left(\mathrm{gr} / \mathrm{cm}^{3}\right)$ & 2.44 & 2.44 & 2.44 & 2.47 & 2.51 \\
\hline $\begin{array}{l}\text { Dynamic Shear } \\
\text { Modulus (Mpa) }\end{array}$ & $1.34 \mathrm{E}+07$ & $1.34 \mathrm{E}+07$ & $1.38 \mathrm{E}+07$ & $1.44 \mathrm{E}+07$ & $1.52 \mathrm{E}+07$ \\
\hline $\begin{array}{l}\text { Dynamic Young's } \\
\text { Modulus ( Mpa) }\end{array}$ & $3.40 \mathrm{E}+07$ & $3.40 \mathrm{E}+07$ & $3.49 \mathrm{E}+07$ & $3.68 \mathrm{E}+07$ & $3.94 \mathrm{E}+07$ \\
\hline
\end{tabular}

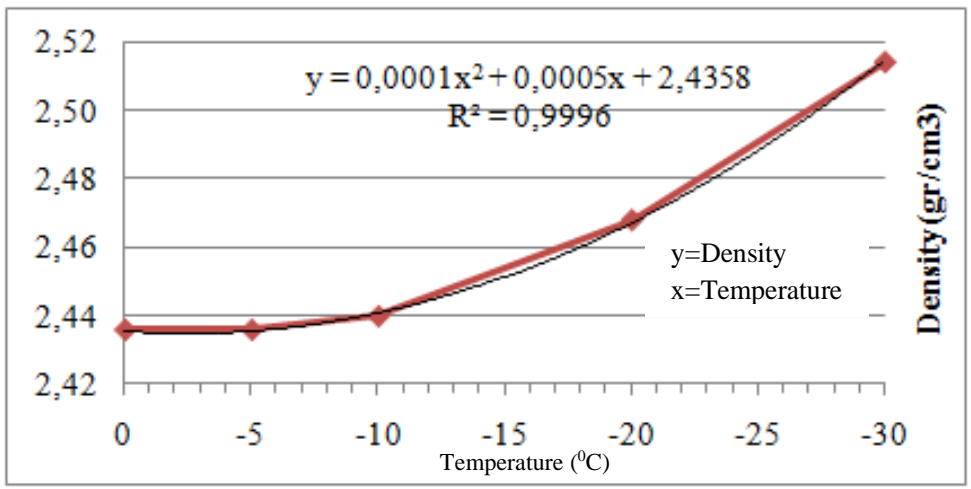

(a)

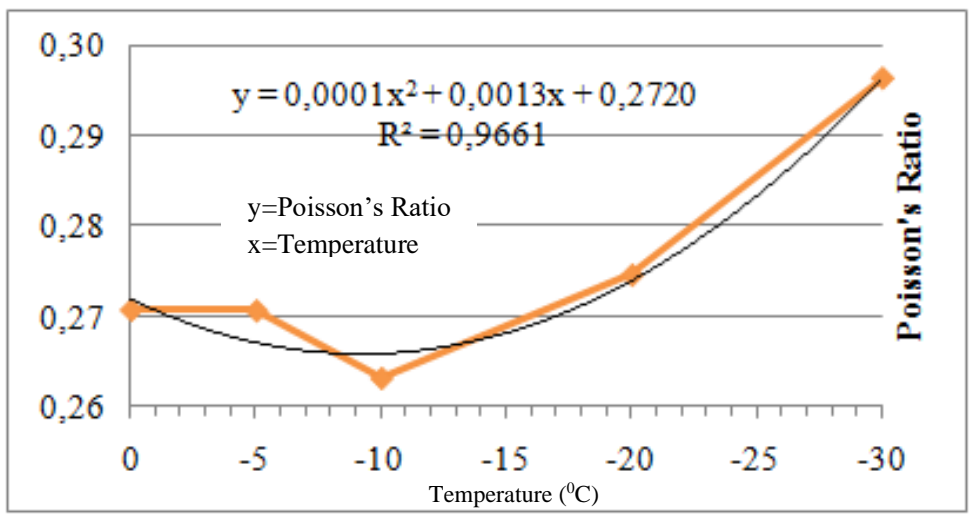

(b)

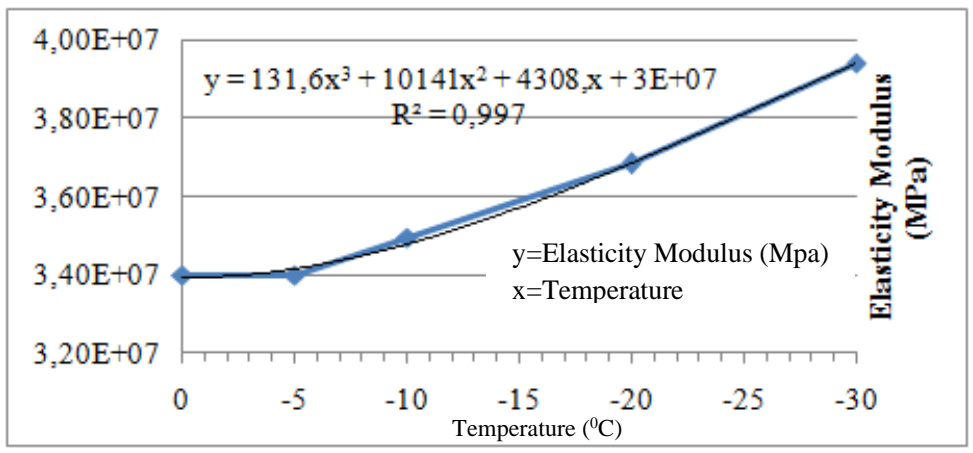

(c)

Fig. 7. (a) Density, (b) Poisson's Ratio and (c) The elasticity modulus versus temperatures for frozen concretes (C30) 


\subsection{Finite element model}

A prototype reinforced concrete mosque was modeled by finite element method to determine the effective frequency for the analyses which being performed by ANSYS [14]. The minaret has two balconies. The solid and finite element models of the prototype reinforced concrete mosque are shown in Fig.8 (a-b). From inside, a cylindrical shaft of constant inner diameter extends from the bottom square base up to the level of the balcony. Three-dimensional (3D) SOLID45 elements, which exhibit quadratic displacement behavior, were used for modeling both the minaret body and the internal helical stair. The element has 8 nodes and three degrees of freedom per node, translations in the nodal $\mathrm{x}, \mathrm{y}$, and $\mathrm{z}$ directions.
The modulus of elasticity, Poisson's ratio and mass density of concrete material are taken according to low temperatures (Table 1). The frequencies according to different low temperatures are illustrated in Table 2 and three effective frequency variations with the low temperatures are plotted in Fig.9 (a-c). It is seen from Table 2 and Fig.8, an increase in the cold effect of causes a visible increasing in the frequencies of the minaret system. As a result, the effects of low temperatures on modal response of the prototype reinforced concrete minaret may cause the changes in its seismic behaviors. These unexpected modal changes can cause the unpredictable seismic behavior of buildings during the earthquake. This is not desirable in terms of civil engineering field.

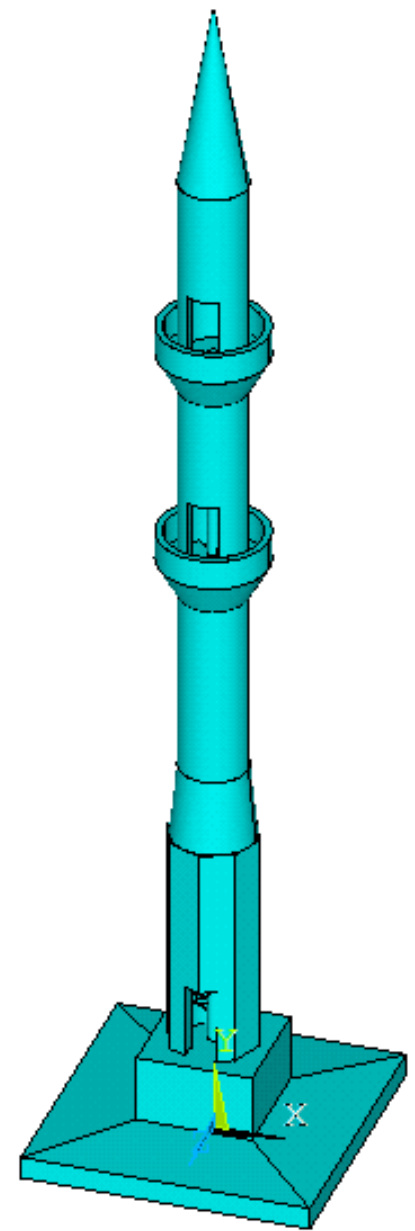

(a)

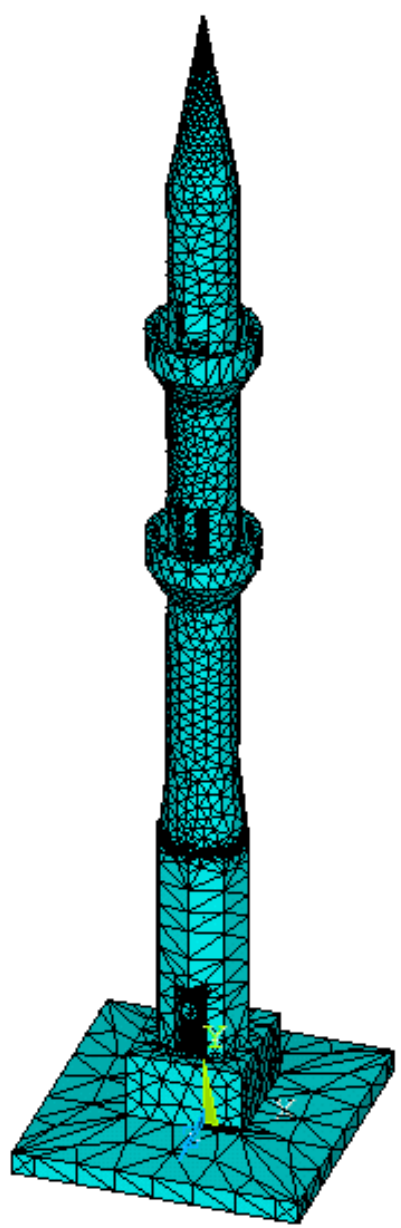

(b)

Fig. 8. (a) Solid and (b) finite element models of prototype reinforced concrete minaret 
Table 2. The frequencies of the minaret system with respect the low temperatures

\begin{tabular}{ccccc}
\hline \multicolumn{5}{c}{ Frequency $(\mathrm{Hz})$} \\
\hline Number & $-5^{\circ} \mathrm{C}$ & $-10^{\circ} \mathrm{C}$ & $-20^{\circ} \mathrm{C}$ & $-30{ }^{\circ} \mathrm{C}$ \\
\hline 1 & 39.078 & 39.570 & 40.407 & 41.557 \\
2 & 40.782 & 41.298 & 42.169 & 43.361 \\
3 & 182.57 & 184.87 & 188.78 & 194.15 \\
4 & 198.84 & 201.35 & 205.60 & 211.43 \\
5 & 416.05 & 422.81 & 430.21 & 437.73 \\
6 & 449.70 & 455.46 & 465.00 & 477.97 \\
7 & 468.19 & 474.19 & 484.12 & 497.57 \\
8 & 697.30 & 706.33 & 721.03 & 740.64 \\
9 & 765.30 & 775.27 & 791.33 & 812.81 \\
10 & 800.76 & 811.27 & 828.00 & 850.26 \\
\hline
\end{tabular}

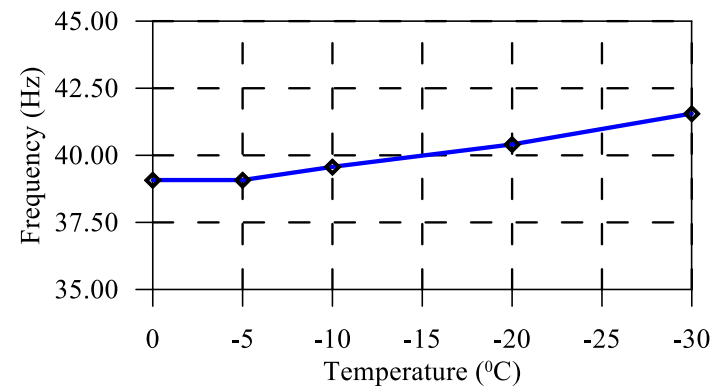

(a)

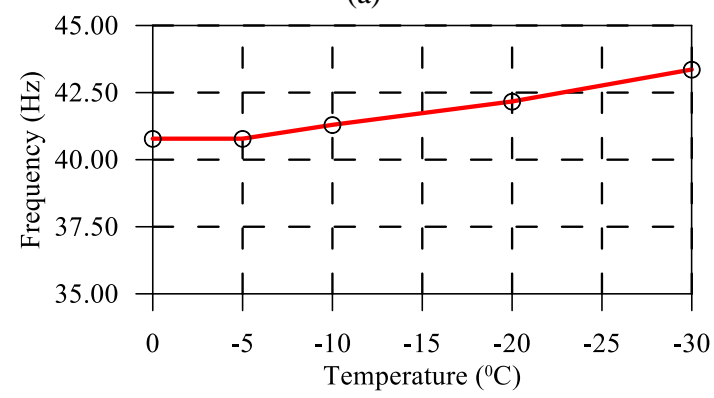

(b)

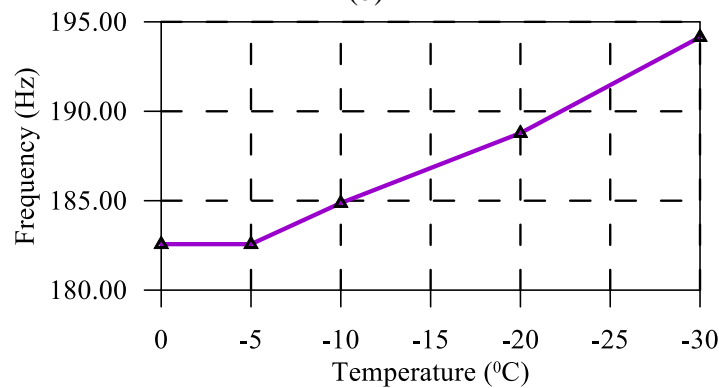

(c)

Fig. 9. (a) First, (b) second and (c) third frequencies of the minaret system with respect the low temperatures 


\section{Conclusion}

This study investigates the effects of seasonal low temperature on the dynamic behaviors of reinforced concrete minarets, which was built in seismic zones. For this aim, by taking into consideration the actual dimensions of a reinforced concrete minaret, prototype scale model of it was made in the laboratory. The model was placed into a large volume freezer and then exposed to low temperatures. The prototype minaret model was analyzed by using the shaking table. The two accelerometers placed on the minaret give the acceleration time history values according to different low temperatures.

The maximum acceleration values obtained from the analyses showed that seasonal low temperatures affect the modal response and accordingly, the seismic behavior of the prototype reinforced concrete minaret model. Based on these results, during the earthquake, the seismic behaviors of actual structures built in earthquake regions are affected by the seasonal low temperatures. Therefore, during an earthquake, in order to estimate more accurately the seismic behavior of structures built in cold regions, the necessity to consider the seasonal low temperature effects reveals.

\section{References}

[1] Madugula MKS, Wahba YMF, Monforton GR (1998) Dynamic response of guyed masts. Engineering Structures 20(12): 1097-1101.

[2] Wang D-Y, Zhu Y-L, Ma W, Niu Y-H (2006) Application of ultrasonic technology for physicalmechanical properties of frozen soils. Cold Regions Science and Technology 44: 12-19.

[3] Tan X, Chen W, Yang J, Cao J (2011) Laboratory investigations on the mechanical properties degradation of granite under freeze-thaw cycles. Cold Regions Science and Technology 68: 130138.

[4] Rose J. Ultrasonic Waves in Solid Media. Cambridge University Press, Cambridge, UK, 1999.

[5] Song I, Suh M, Woo Y, Hao T (2004) Determination of the elastic modulus set of foliated rocks from ultrasonic velocity measurements. Engineering Geology 72: 293-308.

[6] Abo-Qudais S (2005). Effect of Concrete Mixing Parameters on Propagation of Ultrasonic Waves. Construction and Building Materials 19(4), 257263.

[7] Bucur V (2005) Ultrasonic techniques for nondestructive testing of standing trees. Ultrasonics 43(4): 237-239.

[8] Yang Z, Dutta U, Xiong F, Biswas N, Benz H (2008) Seasonal frost effects on the dynamic behavior of a twenty-story office building. Cold Regions Science and Technology 51: 76-84.

[9] Li S, Lai Y, Zhang M, Jin L (2009) Seismic analysis of embankment of Qinghai-Tibet railway. Cold Regions Science and Technology 55: 151159.

[10] Gao GY, Chen QS, Zhang QS, Chen GQ (2012) Analytical elasto-plastic solution for stress and plastic zone of surrounding rock in cold region tunnels. Cold Regions Science and Technology 72: $50-57$.

[11] Qi J, Ma W, Sun C, Wang L (2006) Ground motion analysis in seasonally frozen regions. Cold Regions Science and Technology 44: 111-120.

[12] Yang ZJ, Zhu D, Marx E, Biswas N (2008) Seasonal frost effects on the soil-foundationstructure interaction system. Journal of Cold Regions Engineering 21: 108-121.

[13] Haciefendioğlu K (2010) Seasonally frozen soil's effect on stochastic response of masonry minaretsoil interaction systems to random seismic excitation. Cold Regions Science and Technology 60(1): 66-74.

[14] ANSYS Swanson Analysis System, US 2012. (Temporary License by Figes A.Ş., Turkey). 